\title{
Los judíos y la medicina. Una profesión en dos contextos.
}

\author{
Jews and medicine two contexts for a profession.
}

\author{
Adriana Hernández \\ Adriana@sangeronimo.ohc.cu \\ Colegio Universitario San Gerónimo de La Habana
}

\section{Resumen}

El artículo versa sobre el tradicional vínculo de los judíos con la ciencia médica, sobre todo en la península Ibérica durante la Edad Media, donde reconocidas figuras de origen hebreo practicaron el ejercicio de la Medicina con notable éxito en el mundo conocido de entonces ¿Qué hizo posible que los judíos desarrollaran la ciencia médica en tiempos de oscuridad? Además, se analiza la vigencia de la profesión en los tiempos modernos, particularmente en la comunidad hebrea cubana de la primera mitad del siglo XX, según la información aparecida en el fondo bibliográfico Abraham Marcus Matterin, conservado por el Archivo Histórico de la Oficina del Historiador de la Ciudad de La Habana.

Palabras claves: judíos, medicina, profesión, comunidad.

\section{Abstract}

The article deals with the traditional bond of the Jews with medical science, especially in the Iberian Peninsula during the Middle Ages, where recognized figures of Hebrew origin practiced medicine with remarkable success in the world known at that time. What made it possible for the Jews will develop medical science in times of darkness? In addition, the validity of the profession in modern times is analyzed, particularly in the Cuban Hebrew community of the first half of the 20th century, according to the information published in the bibliographic collection Abraham Marcus Matterin, preserved by the Historical Archive of the Office of the Historian of the City of Havana.

Keywords: Jews, medicine, profession, community.

\section{La Medicina judía en la Edad Media}

A pesar de no existir una literatura médica ni en la Biblia o el Talmud, ni en la época helenística, la profesión médica se convirtió en una de las preferidas de los judíos hispánicos en la Edad Media, sobre todo entre los siglos X y XIII cuando floreció en la Península el centro del pensamiento judío más importante de Occidente. La muchas veces ponderada "buena convivencia" de las tres culturas -musulmana, cristiana y judía- propició el desarrollo de una cultura y una espiritualidad hebrea 
autónoma que alcanzó elevadas cuotas en la exégesis bíblica y en los comentarios talmúdicos, pero también en las llamadas ciencias liberales, en las que la Medicina tuvo un desarrollo notable.

Los judíos reemplazaron a los árabes en el ejercicio de la Medicina a tal punto que, a lo largo del siglo XII, la profesión pasó a ser monopolio casi exclusivo de los hebreos, hasta que ciertos sectores urbanos de la sociedad cristiana, con la ayuda de la Iglesia y en ocasiones de la monarquía, pudieron formarse en las incipientes aulas universitarias ${ }^{1}$. El conocimiento que tenían de la herencia médica griega y del saber árabe, hizo de los médicos judíos los más buscados por la corona, los eclesiásticos, la nobleza, los municipios y los particulares en general, a pesar de la prohibición conciliar de 1263 que impedía a los cristianos contratar los servicios de practicantes judíos. Por otra parte, la profesión médica presentaba notables ventajas, no interfería en el cumplimiento de sus preceptos religiosos (los hebreos nunca vieron contradicción entre su fe y la práctica médica para curar), les posibilitaba tener acceso a las cortes y centros de poder, y podía ser retomada con facilidad en caso de tener que trasladarse de un lugar a otro.

La expulsión de 1492 produjo un vacío en la Medicina española, sobre todo en muchas localidades que disponían antes de un médico hebreo, que tardó años en ser cubierto. No obstante, la tradición médica judeo-española no fue eliminada; la vigencia de la profesión continuó, tanto entre los judeoconversos que permanecieron en la Península, como entre los que se vieron obligados a emigrar. ${ }^{2}$

\section{¿Qué hizo posible que los judíos desarrollaran la ciencia médica en tiempos de oscuridad?}

- La relativa tolerancia musulmana, que les permitió a los judíos de la Península desarrollar su potencial intelectual, no solo religioso, sino también en las ciencias y las artes. Fueron filósofos, diplomáticos, tesoreros, médicos, matemáticos, botánicos, astrónomos, traductores, lingüistas, administradores, poetas... judíos los que les valieron a los siglos X al XII ser llamados los "siglos de oro" de la judería Ibérica. Pero la "España de las tres culturas" no significó que musulmanes, judíos y cristianos estuvieran en un plano de igualdad social, sino que los musulmanes, como grupo dominante, concedieron tanto a judíos como a cristianos el rango de dimmíes (protegidos), ${ }^{3}$ y toleraban el ejercicio de su religión a cambio del pago de impuestos especiales. Esta "relativa buena convivencia" propició la participación activa de los judíos en todos los aspectos de la vida y el logro de posiciones bien cimentadas dentro de la sociedad Ibérica. Por otra parte, la llegada de notables maestros hebreos procedentes de Babilonia o del

${ }^{1}$ (Blasco, PDF) plantea que preferentemente en Salerno y Montpellier. Desde finales del siglo XIII, la Universidad (o Estudio General) desempeñó una función clave en la preparación, adquisición y difusión de los conocimientos médicos a nivel europeo.

${ }^{2}$ Barkai (1993) hace referencia a un tratado sobre la pestilencia escrito por Al Yahudi Ibn Ibrhim Al Isbani en el siglo XVI dedicado al sultán otomano Bayazid, en el que se demuestra el aporte de la tradición médica Ibérica al Imperio turco otomano.

${ }^{3}$ Considerados como "gentes del Libro" (Biblia) (N.A). 
Magreb facilitó una producción intelectual que les permitió incidir de la manera que lo hicieron en la cultura europea y universal. Se destacaron entre otras, figuras de la talla Ibn Shaprut ( siglo X) médico y canciller de la corte de los califas omeyas en Córdoba, protector de los suyos y gran impulsor de la cultura hebrea, Ibn Nagrela en Granada, y el cimero Maimónides o Rambán (Moisés ibn Maimón) nacido en Córdoba en el siglo XII, gran filósofo y médico en la corte del sultán Saladino I, y líder de la comunidad judía del Cairo hasta su muerte ocurrida en 1204.

- Los judíos como "puente" entre culturas y saberes. Una buena ilustración de este fenómeno la encontramos en la declaración hecha por la célebre poetisa chilena Gabriela Mistral en uno de sus ensayos dedicado a Waldo Frank en "Repertorio Americano"; ${ }^{4}$ dijo: "Un judío es el relacionador natural de orientes y occidentes en cualquier campo -cultura, política o religión-, y es el puente, si lo hay, para las dos orilla enconadas" (Hochstein, p. 53-c). La dispersión de las comunidades judías por el mundo oriental y quizá también por el occidental puede ser datada desde los siglos VIII - V a.n.e., pero definitivamente en el I n.e, con el trasiego de personas, comerciantes y esclavos en el mundo romano, la presencia hebrea en Europa occidental es incuestionable y está avalada por descubrimientos arqueológicos. ${ }^{5}$ Entre las comunidades judías dispersas del mundo conocido de entonces existían vínculos, fundamentalmente comerciales y religiosos, lo que permitió a los judíos de Occidente (Sefarad) durante toda la Edad Media, estar en contacto con lo más adelantado de la Medicina que se practicaba en los grandes centros urbanos del Oriente, ${ }^{6}$ en momentos en que la Europa cristiana se replegaba sobre sí misma, separada, como estaba, del mundo oriental por el mar Mediterráneo en poder del Islam.

- Sus vínculos con la ciencia médica árabe, pues fueron los judíos quienes, por sus contactos, movilidad y conocimiento de la lengua, absorbieron el conocimiento médico atesorado por los árabes, Rhamzés, Abulcasis, Avicena, Ibn Wafid, Avenzoar y Averroes, entre otros. La contribución principal de los árabes a la Medicina fue la preservación de los textos médicos griegos que de otra manera se hubieran perdido, y su incorporación -combinándolos con algunos elementos de la Medicina clásica de la India y Roma- a su práctica médica cotidiana. De esta manera, el canon de Galeno y los principios de Hipócrates fueron

\footnotetext{
${ }^{4}$ Waldo Frank (1889- 1967), escritor norteamericano de origen judío, autor de América Hispana (1931), obra interpretativa sobre Latinoamérica que fuera elogiada por la Mistral como cabal interpretación de la realidad hispanoamericana, que ella atribuía a la condición de su autor de judío norteamericano.

${ }^{5}$ En Tortosa se encontró una lápida trilingüe escrita en hebreo, griego y latín que data del siglo VI n.e. y al parecer corresponde a una sepultura. Aunque la "magen David" (estrella de David) no se constituyó en símbolo judío hasta el siglo XVIII, María Estanyol Fuentes en su "Historia de los judíos catalanes" se refiere al hallazgo en Ampurias en el siglo I n. e. de un sello de cerámica que tiene grabado el mismo símbolo, y en el centro, una letra hebrea. (Etanyol, p. 14).

${ }^{6}$ Fundamentalmente en Bizancio y Persia (Amaro Cano, PDF)
} 
introducidos en Europa por las obras médicas escritas en árabe, muchas veces traducidas por judíos. El mismo Maimónides, escribió muchos de sus aforismos médicos en árabe, que después fueron traducidos al hebreo y al latín. Es un hecho que la cultura judía se vio enriquecida por los aportes de la civilización con la que entró en contacto; de hecho, los judíos, sin una literatura médica precedente -solo con principios de higiene corporal, mental y espiritual propios de su religión- fueron capaces de sustituir a los árabes en el ejercicio de la Medicina en la Península Ibérica.

En 1993 R. Barkai publicó un excelente estudio sobre la historia de la Medicina donde formula las siguientes preguntas ¿Hubo Medicina judía? ¿Tuvieron los médicos judíos diagnósticos y métodos de curación propios? Si nos referimos a la Medicina judía como literatura científica, en términos estrictamente lingüísticos, la respuesta es clara, sí hubo literatura médica judía escrita en judeoárabe, hebreo, y judeo- español, con todo lo que ello implica en la traducción de términos propiamente médicos, pero desde el punto de vista curativo, la base de la Medicina de las tres culturas monoteístas de la Edad Media fue la tradición médica griega.

No obstante, como argumenta el propio Barkai (p. 476) "es evidente que cada cultura encontró y asimiló la Medicina griega por métodos lingüísticos, tradiciones y conceptos religiosos de su propia herencia", esto, desde nuestro punto de vista significa, que la mezcla de los principios morales y dietéticos- sanitarios contenidos en los libros sagrados judíos, su concepto del hombre como un todo -espíritu, alma y cuerpo-, más la herencia médica griega -fundamentalmente hipocrática-, así como sus contactos con la ciencia médica árabe -recopiladora de saberes- condujo al éxito de los judíos en el ejercicio de la Medicina durante la Edad Media.

El trabajo de referencia más importante hasta hoy realizado sobre contribuciones judías a la ciencia medieval, fue realizado por el bibliógrafo y erudito alemán Moritz Steinchmeider a finales del siglo XIX (Ramírez, 1948). Steinchmeider, que examinó cientos de manuscritos árabes y hebreos, registra no menos de 2 mil ciento sesenta y ocho médicos judíos que ejercieron la Medicina entre los siglos XII y XVIII. ${ }^{7}$ Pero a más de las contribuciones de los hebreos a la ciencia médica medieval, tales han sido sus aportes a la Medicina europea moderna que, además de Freud -padre del psicoanálisis-, muchas enfermedades presentes en la actualidad se conocen por el nombre de sus descubridores judíos. ${ }^{8}$ Quizás sea esta relación la que motivó la aguda sentencia del distinguido escritor católico Alfonso F. Ramírez, recogida en una importante publicación hebrea cubana del siglo XX: "si un antisemita padece cualquier enfermedad -infecciosa, viral, hereditaria- no deben

\footnotetext{
${ }^{7}$ Para ver referencias a la obra de Moritz Steinchmeider se puede consultar también Barkai, 1993, p. 478.

${ }^{8}$ Por ejemplo, el sarcoma de Kaposi debe su nombre al célebre dermatólogo húngaro Moritz Kaposio, quien describió la enfermedad en Viena en 1892; el síndrome de Crhon, es una enfermedad de inflamación intestinal descrita por los médicos Burril B. Crhon (de quien toma su nombre) y sus colegas Ginzburg y Oppenhaimer del hospital Monte Sinaí en Nueva York en 1932. Algunos campos investigativos están indisolublemente vinculados a los nombres de sus investigadores, como Paul Ehrlich, célebre por sus estudios serológicos sobre las enfermedades venéreas NA.
} 
aceptar los métodos diagnósticos más comunes, ni mucho menos curación, pues casi todos cuanto existen han sido obra del genio judío" (Ramírez, 1948, p. 49-c).

\section{Una profesión documentada}

Reconocimiento en Cuba de la profesión médica como una tradición entre los hebreos

Un recorrido por la historia de la Medicina y el papel que los hebreos como grupo social han jugado tradicionalmente en el ejercicio de esta profesión, fue el tema de la conferencia impartida por el destacado intelectual hebreo- cubano Abraham Marcus Matterin en la sede de la Logia Benai Berith Maimónides de La Habana, el 6 de diciembre de 1950 en ocasión del Día Panamericano del Médico que se celebra en Cuba cada 3 de diciembre desde 1933, en homenaje al natalicio del científico cubano Carlos J. Finlay Barrés, descubridor del vector trasmisor de la fiebre amarilla. La información emerge de uno de los expedientes del Fondo Abraham Marcus Matterin (F. MM), ${ }^{9}$ preservado por el Archivo Histórico (AH) de la Oficina de Historiador de la Ciudad de La Habana $(\mathrm{OHC})$; el fondo Marcus Matterin -documental y fotográfico- constituye un valioso testimonio de la inserción económica y social de los hebreos a la sociedad cubana del siglo XX y colección de obligada consulta para todo aquel que se interese por la historia de los hebreos en Cuba y sus aportes culturales.

\section{Una comunidad revelada en un fondo}

El hecho de que en esta ocasión (6 de diciembre de 1950) la comunidad judía cubana homenajeara a los médicos hebreo- cubanos con una actividad a la que asistieron más de 300 personas, 20 médicos hebreos y 10 familias de médicos ausentes (Ver foto 1), no fue un hecho fortuito. Responde a la descripción de una colectividad que en la década del 50 del pasado siglo había alcanzado un nivel de autoconfianza y aceptación inusual en otros contextos latinoamericanos (Elkin, 2014 pp. 249253), que le permitió, después de culminar una primera fase de inserción socioeconómica, avanzar hacia nuevas formas de integración social en las que una joven generación de hebreos- cubanos se posesiona en las profesiones liberales, y dentro de ellas, la Medicina ocupó un lugar de honor. Los judíos, como minoría de siempre perseguida, sabían en la Cuba del siglo XX lo mismo que supieron en la España medieval: lo único que no puede confiscarse es el conocimiento, por ello, esa

\footnotetext{
${ }^{9}$ Abraham Marcus Matterin fue un escritor, periodista, bibliógrafo, y sobre todo un promotor cultural hebreocubano que nació en Kaunas, Lituania y vino a Cuba junto a su familia en la masiva oleada migratoria de 1924. La labor intelectual que desplegó, no solo dentro de la comunidad hebrea, sino también en la sociedad cubana dando a conocer los valores universales de la cultura judía y los aportes de este grupo social al patrimonio nacional cubano, le ha valido el calificativo de "figura de mayor relevancia de la intelectualidad hebreo- cubana” (Hernández, 2011, p. 11) y “el judío más integrado de Cuba” (Corrales, 2018). Al fallecer, el 2 de mayo de 1983, la Dirección de Vivienda de la ciudad de La Habana cerró su casa por no haber herederos. Meses después, Adela Dworin, colaboradora y amiga de Matterin, actual presidenta de la Comunidad Hebrea de Cuba, contactó con el Dr. Eusebio Leal Spengler, historiador de la ciudad de La Habana para garantizar la preservación de los libros, fotografías, recortes de prensa y otros documentos personales de Matterin, surgiendo así el Fondo Abraham Marcus Matterin en el Archivo Histórico de la Oficina del Historiador.
} 
concentración en el estudio como forma de logar aceptación y movilidad social. Abogados, médicos, dentistas, ingenieros, arquitectos y contadores públicos judíos llenaron los directorios de profesionales de la década del 50, lo que reflejó la asimilación por parte de los judíos cubanos de los valores de la élite nacional -donde la Medicina ya ocupaba un lugar cimero- a partir de su nuevo estatus dentro de las clases medias. ${ }^{10}$

La profesión médica fue frecuente entre los hijos de los hebreos cubanos, aún entre aquellos últimos en llegar; así lo sugiere una tarjeta de invitación del Comité Juvenil Hebreo al homenaje del joven refugiado polaco Luis Bernardo Fischleder, graduado de Medicina en Cuba en 1945 (Ver foto 2). La presencia de la profesión entre los hebreos parece repetirse en otros países de América Latina, como podría pensarse por una fotografía enviada desde México por el mismo Dr. Fishleder a Marcus Matterin, donde aparece un grupo de médicos hebreos del instituto de Cardiología Nacional de México, algunos de ellos también refugiados. (Ver fotos 3 y 4).

El creciente número de estudiantes de Medicina con apellidos hebreos, tanto ashkenazís como sefarditas, en la Universidad de La Habana avanzada la década del 40’fue frecuentemente citado por la prensa judía de la época; la revista Israelia, fundada en 1950 para destacar temas fundamentalmente culturales y propiciar la compenetración hebreo- cubana, ${ }^{11}$ mantuvo una columna exclusivamente dedicada a la vida social de los médicos hebreos denominada "Noticiario Médico hebreo- cubano". ${ }^{12}$ Muchos de estos jóvenes, a diferencia de la élite profesional nacional, que con frecuencia encontraba más rentable obtener un puesto en el gobierno, ${ }^{13}$ se vincularon a asociaciones profesionales internacionales y desarrollaron su práctica médica fuera de Cuba. ${ }^{14}$

No obstante, hubo notables médicos hebreo- cubanos en importantes instituciones nacionales, que, a pesar de su desempeño como especialistas, se caracterizaron por una honda preocupación social por

\footnotetext{
${ }^{10}$ Martitza Corrales lo explica a partir de un chiste popular cubano: "Una madre cubana está en un parque con sus niños y otra señora le dice: ¡Que lindos niños! ¿Cuántos años tienen? Y ella responde: el médico cuatro y el abogado dos (Corrales, (2002, p. 86).

${ }^{11}$ Israelia (1950). "Ponche de honor por el primer número de Israelia”. Año I, No. III, 1 - 15 Octubre.

${ }^{12}$ Ver "Noticiario Médico hebreo- cubano" en Israelia (1951) Año 2, No. VII Septiembre-Octubre de 1951, p. 13; Israelia (1952) Año 3 No. IX, Edición Especial, pp. 25 y 31.

13 En Cuba, un "título" no necesariamente representaba el nivel de ingreso correspondiente al mismo, devengado -por ejemplo- en los Estados Unidos. Así, muchos profesionales cubanos optaban por introducirse en la burocracia gubernamental, donde el título de "doctor" en Medicina o Leyes, proporcionaba "respetabilidad". En cambio, el camino de la administración pública se mantuvo cerrado para los judíos (N.A).

${ }^{14}$ Israelia (1951, p. 13) "Se encuentran de visita en La Habana... dos medicos, ambos hebreo-cubanos: la Dra. Dora Stryzak, de Nueva York y el Dr. Oscar Leivan (Gronstein) que ejerce en París. La Dra. Stryzak ha sido secretaria de la Unión Sionista de Cuba y el Dr. Leivan (Gronstein) fue fundador del Círculo de Estudiantes Hebreos de Cuba....".
} 
la comunidad de la que formaban parte. ${ }^{15}$ La labor de tos médicos hebreos dentro de la comunidad estuvo dirigida fundamentalmente a la asesoría y participación directa en asociaciones caritativas y de ayuda a los necesitados que desde los primeros momentos de la formación institucional comunitaria se hicieron presentes. Así, el Dr. Moisés Mitrani, primer hebreo graduado de Medicina en Cuba y doctor del cuerpo médico del hospital de Emergencias de La Habana, ocupó importantes cargos dentro la directiva del Comité de Protección a Tuberculosos y Enfermos Mentales, y de Bikur Holim, el primero creado desde 1927 para asistir a pacientes hebreos internados en hospitales cubanos, ${ }^{16}$ y la segunda, asociación de beneficencia creada por la sinagoga sefardita Shevet Ahim.

Por otra parte, el reconocimiento al tradicional vínculo de los hebreos con la Medicina, así como el homenaje a figuras médicas de talla universal constituyó una de las aristas fundamentales de la prolífera vida cultural de la comunidad judía cubana en la primera mitad del siglo XX. En el fondo M.M. se recoge la memoria fotográfica de una actividad en la que participó buena parte de la colonia habanera en honor al hematólogo alemán Paul Enrlich dirigida por el propio Marcus Matterin a finales de los 50' en el moderno edificio del recién entonces inaugurado Patronato de la Casa de la Comunidad Hebrea de Cuba (Ver foto 5). Asimismo, la comunidad se preciaba de contar con la amistad de célebres personalidades médicas internacionales no judías, como el doctor Gustavo Pittaluga Fattorini -exiliado antifascista de origen italiano- y el cubano Domingo Gómez Gimeránez -amigo personal de Albert Einstein- quienes participaron como invitados en actividades organizadas por la Agrupación Cultural Hebreo- cubana. ${ }^{17}$ (Fondo M.M, legajo 4, 9-10)

Entre los líderes de la comunidad, también hubo médicos, el ya mencionado Moisés Mitrani que ocupó notables cargos dentro de la comunidad y se destacó por su preocupación social (Mitrani, 1947); el doctor Enrique Eiber, quien fuera presidente de la Agrupación Cultural Hebreo Cubana en 1955; el Dr. Gurtwitz, odontólogo de la localidad habanera de Cojimar y amigo personal de Marcus Matterin, y el mismo José Miller Fredman, presidente de la comunidad judía cubana hasta su muerte ocurrida en 2006, fue un conocido odontólogo y cirujano maxilofacial de las Fuerzas Armadas Revolucionarias, hasta 1968 (Corrales, 2007).

\section{Los judíos y la Medicina, a manera de conclusión}

El ejercicio de la Medina ha sido una profesión con la que los judíos tradicionalmente se han sentido identificados. Cultivar conocimientos sobre el cuidado y la preservación de la vida humana

\footnotetext{
${ }^{15}$ Mitrani, M. (1947). Por un hospital hebreo en La Habana. Almanque Hebreo Vida Habanera, La Habana: Editorial Vida Habanera, pp. 25-c- 29-c.

${ }^{16}$ El Comité contrataba los servicios de clínicas cubanas para atender a hebreos necesitados aquejados de estas enfermedades; además, pagaba cuotas de pensionistas en instituciones médicas mutualistas cubano españolas, como la clínica Covadonga, o la Dependiente.

${ }^{17}$ Agrupación Cultural Hebreo- cubana, creada por Marcus Matterin en 1953 con el objetivo de dar a conocer los valores de la cultura hebrea y propiciar un intercambio entre intelectuales hebreos y cubanos (N.A).
} 
ha sido para ellos, no solo la realización de la suprema vocación universalista del judaísmo, sino una forma de conservar la propia existencia.

Las particularidades históricas y contextuales de la Península Ibérica durante la Edad Media les permitieron llevar la profesión hasta un lugar cimero y el nombre más importante en la vida judía de los "siglos de oro"-Moisés Ibn Maimón (Maimónides)- está inexorablemente vinculado a la Filosofía, pero también al ejercicio de la Medicina hasta hoy.

La vigencia de la profesión Médica en las comunidades hebreas modernas, ilustra la desde entonces sostenida tendencia entre los hebreos a concentrarse en el estudio de las llamadas profesiones liberales -y dentro de ellas la Medicina- como una forma de logar aceptación y la movilidad social.

El valor atribuido a la profesión médica dentro de la comunidad hebrea cubana de la primera mitad del siglo XX, estribó, más que en la cantidad de jóvenes hebreos que lograron graduarse, en el reconocimiento social y cultural que tuvo la profesión médica y los médicos dentro de la comunidad.

\section{Referencias bibliográficas}

- Amaro C., M del C. (s.f) El mundo árabe y la ciencia médica (PDF) https://docplayer.es/17589731-Titulo-el-mundo-arabe-y-la-medicina-autora-maria-del... (consultado mayo 2019).

- Barkai, R. (1993). Perspectivas para la historia de la medicina judía española, Espacio, Tiempo y Forma, Serie III, Historia Medieval, t. 6, p. 475- 492. http://revistas.uned.es/index.php/ETFIII/article/viewFile/3568/3425 (consultado mayo 2019).

- Bejarano, M. (1995). La comunidad hebrea cubana, la memoria y la historia. Universidad hebrea de Jerusalén: Instituto Avraham Harman de Judaísmo Contemporáneo.

- Blasco, A. (s.f) judíos y Medicina. La Espiral, Espacio para el pensamiento y la cultura del valle del Ebro, Universidad de Zaragoza. http://webs.ucm.es/info/hebrea/Asuncion.Blasco.Judios.y.Medicina.pdf (consultado enero 2019).

- Corrales, M. (2007). La isla elegida. Los judíos en Cuba. La Habana: Editorial Ciencias Sociales.

- Corrales, M. (2002). Los judíos en Cuba republicana. Debates Americanos, enerodiciembre (12), 81-90.

- Corrales, M. (2007). Cuba, paraíso recobrado para los judíos. En G. Chailloux (Coord.) ¿De dónde son los cubanos? (pp. 165- 231) La Habana: Editorial Ciencias Sociales.

- Corrales, M. (1995). Comportamiento económico y espacial de los comercios e industrias judíos en La Habana: 1902- 1959. En H. Soriano (Comp.) J. Bokser L. y A. Gojman 
(Coord.) Encuentro y Alteridad. Vida y cultura judía en América Latina (pp. 500- 527), México: Fondo de Cultura Económica.

- Corrales, M. (2018). Abraham Marcus Matterin (1916- 1983) Ponencia presentada en Segundo Coloquio Presencias Europeas en Cuba, La Habana: Centro para la Interpretación de las Relaciones Culturales Cuba- Europa Palacio del Segundo Cabo.

- Elkin L., J. (2014). The Jews of Latin American. EE. UU: The Lynne Rienner Publishers, INC.

- Enciclopedia Judaica Castellana. (1951). España. México.

- Etanyol, M.J. (2011) Los judíos catalanes. Barcelona: PPU, S. A.

- Hernández, D. (2004) Órbita de Abraham Marcus Matterin. Tesis de Grado. Facultad de Filosofía, Historia y Sociología, Universidad de La Habana, La Habana, Cuba.

- Hinojosa M., J. (s.f) Los judíos en la España medieval: de la tolerancia a la expulsión. Universidad de Alicante https://rua.ua.es/dspace/bitstream/10045/13209/1/Hinojosa_Judios_España.pdf (consultado abril 2019).

- Hochstein, J. (1949). En tierras americanas se ha reanudado la convivencia hispano israelita. Almanaque Hebreo Vida Habanera, La Habana (1949), 43-c- 51-c.Israelia (1951) Año 2, No. VII Septiembre-Octubre, p. 13.

- $\quad$ Israelia (1952) Año 3 No. IX, Edición Especial, pp. 25 y 31.

- Levine, R. (1993). Tropical Diaspora. The Jewish experience in Cuba. Florida: University Press.

- Matterin, A. M. Fondo bibliográfico. Archivo Histórico (AH), Oficina del Historiador de la Ciudad (OHC).

- Matterin, A. M. Fondo fototeca, AH, OHC.

- Mitrani, M. (1947). Por un hospital hebreo en La Habana. Almanaque Hebreo Vida Habanera, La Habana (1947), 25- 29.

- Ramírez, A.F. (1948). Los valores judíos en la cultura universal. Almanaque Hebreo Vida Habanera, La Habana (1948), 48-c- 49-c.

\section{Fotografías.}




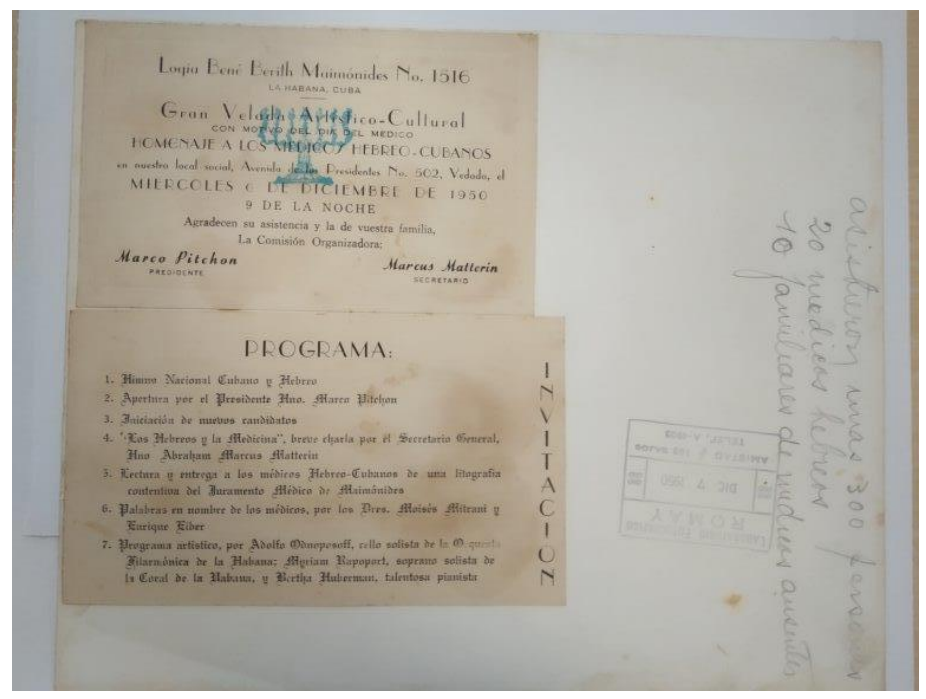

Foto 1. Invitación para el Acto Homenaje a los médicos cubano- hebreos, 6 de diciembre de 1950

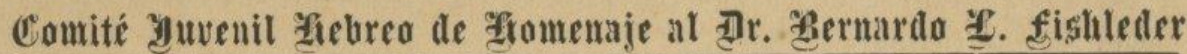

\$r.

tentemus el ḩoutor to intuitarle al

$$
\begin{aligned}
& \text { ga aquete- Concierto } \\
& \text { Zitomenaje } \\
& \text { al } \\
& \text { 刃lr. Bernardo Enis fishleder }
\end{aligned}
$$

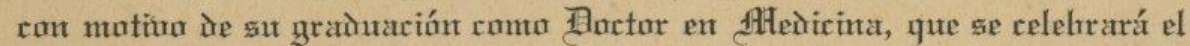

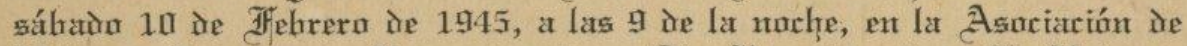

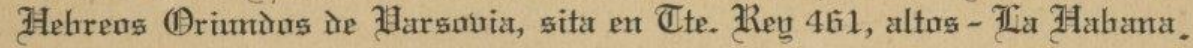

Alapr el Comití:

Clara satanausky.

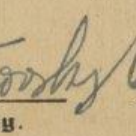

A haham arcus-etlatterin

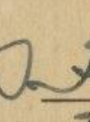

Fentamin 05 reases

Foto 2. Invitación al homenaje al Dr. Luis Bernardo Fischleder 


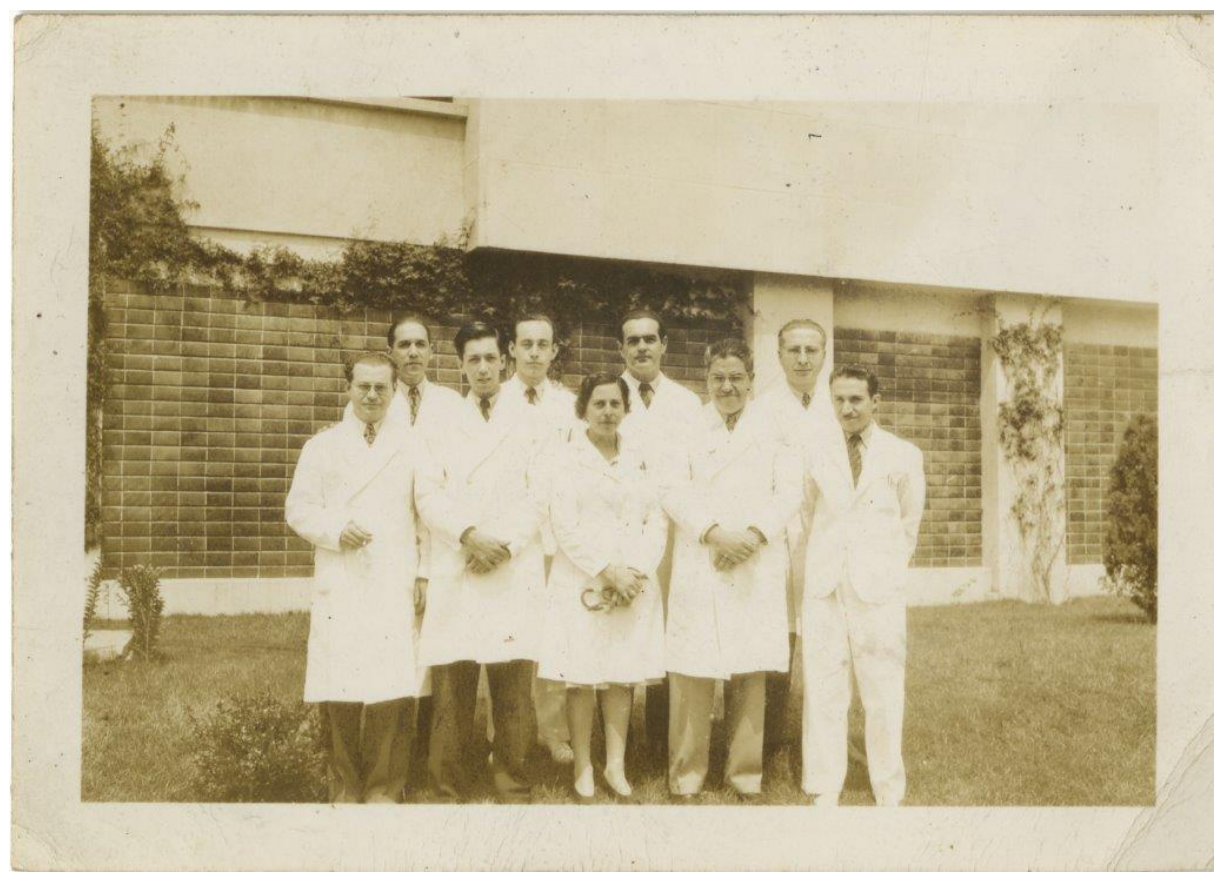

Foto 3. Grupo de médicos del Instituto de Cardiología de México, 1946.

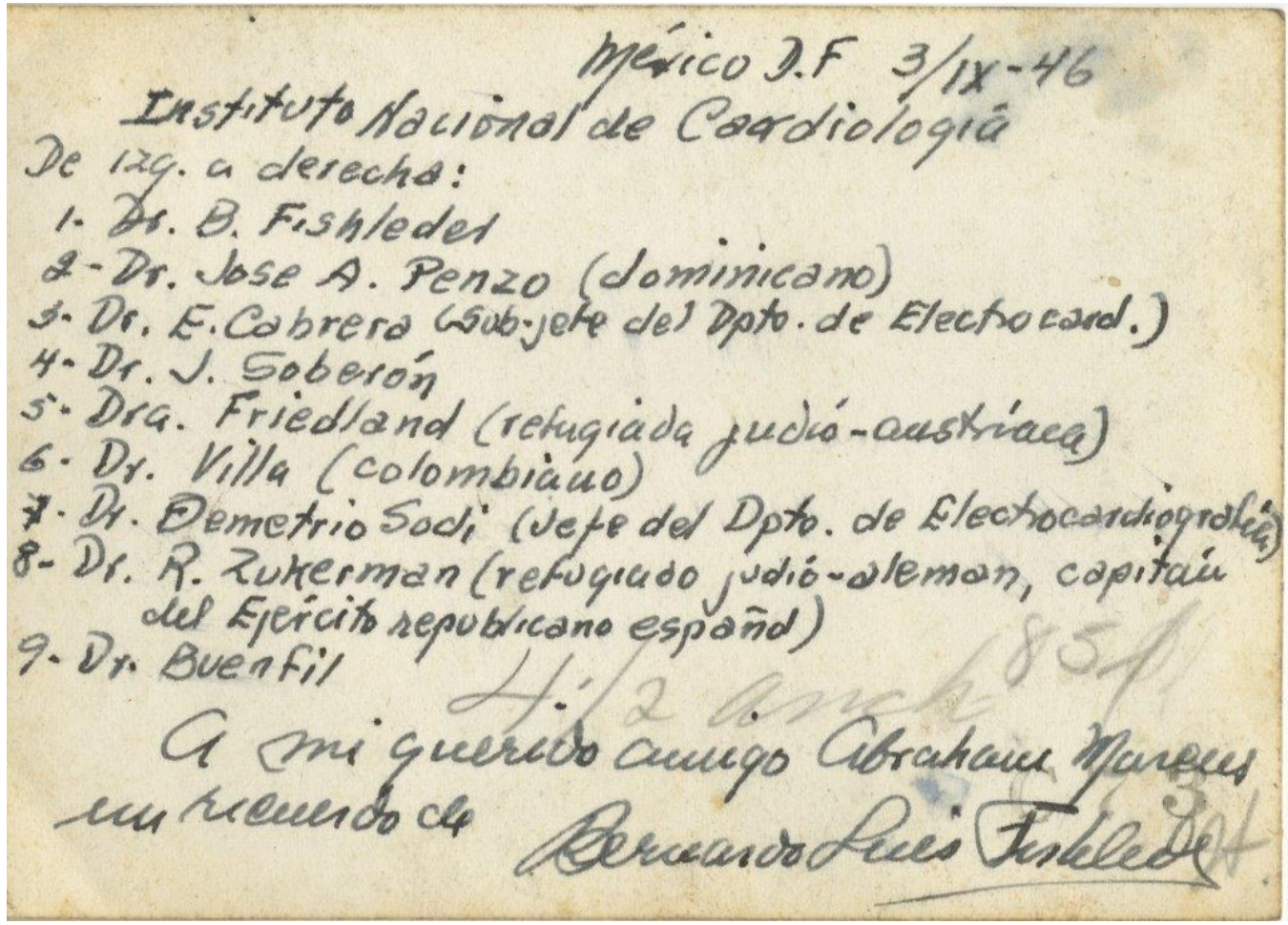

Foto 4. Reverso de la foto anterior, identificando al grupo de Médicos del IC de México, 1946 


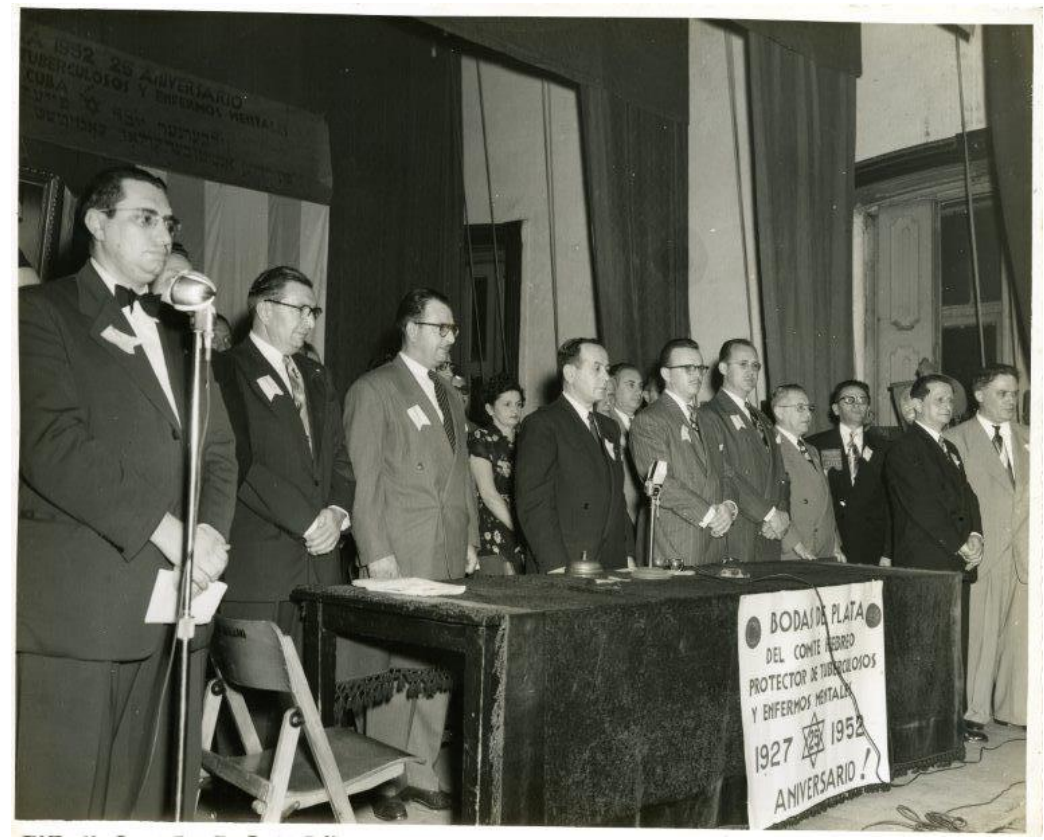

Foto 5. Celebración de las "Bodas de Plata" del Comité de Protección a Tuberculosos y Enfermos Mentales, 1927- 1952

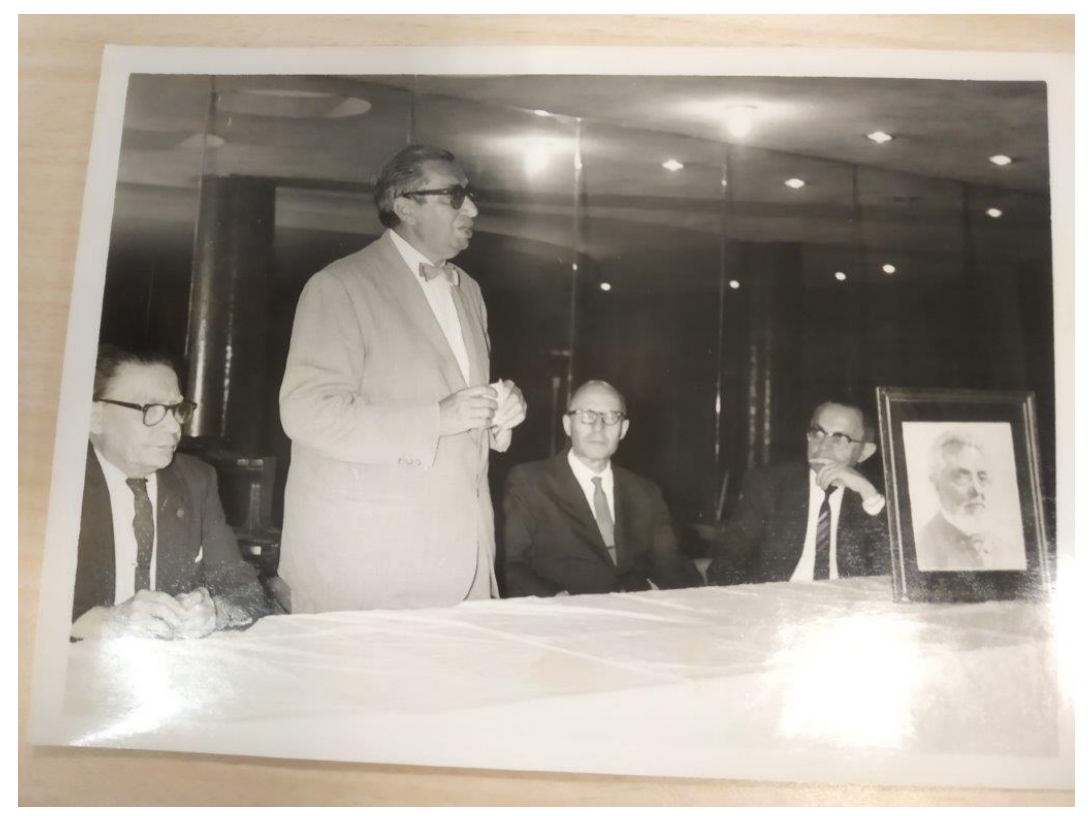

Foto 6. Abraham Marcus Matterin haciendo uso de la palabra en el homenaje a Paul Enrlich en el Patronato de la Casa de la Comunidad Hebrea, años 50’. 